\title{
Levulinic acid from corncob by subcritical water process
}

\author{
Chynthia Devi Hartono ${ }^{1}$ Kevin Jonathan Marlie ${ }^{1} \cdot$ Jindrayani Nyoo Putro $^{2}$. \\ Felycia Edi Soetardjo ${ }^{1}$ - Yi Hsu $\mathrm{Ju}^{2} \cdot$ Dwi Agustin Nuryani Sirodj ${ }^{3}$. \\ Suryadi Ismadji ${ }^{1}$
}

Received: 7 October 2015/Accepted: 17 May 2016/Published online: 27 May 2016

(C) The Author(s) 2016. This article is published with open access at Springerlink.com

\begin{abstract}
The productions of levulinic acid from corncob were carried out by subcritical water process in a temperature range of $180-220^{\circ} \mathrm{C}$, reaction time of 30,45 , and $60 \mathrm{~min}$. The acid modified zeolite was used as the catalyst in the subcritical water process. The ratio between the mass of zeolite and volume of hydrochloric acid in the modification process were 1:5, 1:10 and 1:15. The optimum values of the process variables in the subcritical water process for the production of levulinic acid from corncob were: Temperature of $200{ }^{\circ} \mathrm{C} ; 1: 15$ zeolite to acid ratio; and reaction time of $60 \mathrm{~min}$. The maximum levulinic acid concentration obtained in this study was $52,480 \mathrm{ppm}$ or $262.4 \mathrm{mg} / \mathrm{g}$ dried corncob.
\end{abstract}

Keywords Levulinic acid $\cdot$ Subcritical water $\cdot$ Modified zeolite

Suryadi Ismadji

suryadiismadji@yahoo.com

Felycia Edi Soetardjo

felyciae@yahoo.com

1 Department of Chemical Engineering, Widya Mandala Surabaya Catholic University, Kalijudan 37, Surabaya 60114, Indonesia

2 Department of Chemical Engineering, National Taiwan University of Science and Technology, No. 43, Sec. 4, Keelung Rd, Taipei 106, Taiwan, People's Republic of China

3 Department of Industrial Engineering, Widya Mandala Surabaya Catholic University, Kalijudan 37, Surabaya 60114, Indonesia

\section{Introduction}

Levulinic acid (4-oxopentanoic acid or $\gamma$-ketovaleric acid) is an organic compound with a short-chain fatty acids containing carbonyl group of ketones and carboxylic acids. Levulinic acid is an important chemical platform for the production of various organic compounds. It can be used for the production of polymers, resins, fuel additives, flavors, and others high-added organic substances. This chemical can be produced through several routes [1-7] and one of the most promising processes is the dehydrative treatment of biomass or carbohydrate with various kinds of acids.

Biomass can be used as the precursor to produce levulinic acid and other organic chemicals. The use of biomass as the raw material for the production of levulinic acid in commercial scale was developed by Biofine renewables $[3,7]$. The Biofine process consists of two different stages of processes, the first stage of the process is the production of 5-hydroxymethylfurfural (HMF) while the second stage is the production of levulinic acid [3].

Several studies have reported that various types of homogeneous as well as heterogeneous catalysts have been used for the preparation of levulinic acid from lignocellulosic biomass [2-4, 7-9]. Usually, the homogeneous catalysts are more effective than some of heterogeneous catalysts; however, the drawbacks of the use of homogeneous catalysts for levulinic acid production are associated with the corrosion of the equipment, environmental problem, and re-use of the catalyst. One of the advantages of using heterogeneous catalyst for the production of levulinic acid is the heterogeneous catalyst can be easily recovered and reused [3].

Zeolites have been used as catalysts or catalyst supports in many reaction systems. The properties of zeolites, such 
as porosity, types and the amount of surface acidity, and the type of the structure greatly influence the selectivity and catalytic performance of these materials. A number of synthetic zeolites have been used as the catalyst for the levulinic acid production, however, zeolites with low acidity and porosity gave a poor catalytic performance on the conversion of sugars into levulinic acid [3]. Zeolitetype materials, such as faujasite and modernite, have been used for the synthesis of levulinic acid from $\mathrm{C}_{6}$ sugars and cellulose $[6,8,10,11]$.

Some of agricultural wastes and other lignocellulosic materials have the potential application as the precursors for levulinic acid production [12]. The production of levulinic acid from agricultural waste materials involves two critical steps of processes; the first process is hydrolysis, in the hydrolysis process the hemicellulose and cellulose are converted into $\mathrm{C}_{5}$ and $\mathrm{C}_{6}$ sugars. The second process is dehydration process, in this process the $\mathrm{C}_{5}$ and $\mathrm{C}_{6}$ sugars are dehydrated into levulinic acid and furan derivatives [12].

In this study, the production of levulinic acid from corncob was conducted on subcritical water condition using acid modified zeolite as heterogeneous catalyst. Subcritical water (SCW) process is an environmentally friendly method, which can be applied in various applications, such as extraction, hydrolysis, and wet oxidation of organic compounds. Subcritical water is defined as the hot compressed water $(\mathrm{HCW})$ or hydrothermal liquefaction at a temperature between 100 and $374{ }^{\circ} \mathrm{C}$ under conditions of high pressure to maintain water in the liquid form [13]. At this subcritical condition, water acts as solvent and catalyst for the hydrolysis of cellulose and hemicellulose in the corncob. The use of acid modified zeolite increases the acidity of the system lead to the increase of the hydrolysis and dehydration rate of reactions and subsequently increases the yield of levulinic acid.

To the best of our knowledge, there is no single study used the subcritical water process combined with acid modified zeolite as the catalyst in the production of levulinic acid from lignocellulosic waste material (corncob). The optimum condition for the production of levulinic acid from corncob was determined by Response Surface Methodology (RSM).

\section{Experimental}

\section{Materials}

Corncobs used in this study were obtained from a local market in Surabaya, East Java, Indonesia. Prior to use, the corncobs were repeatedly washed with tap water to remove dirt. Subsequently the corncobs were dried in an oven
(Memmert, type VM.2500) at $110{ }^{\circ} \mathrm{C}$ for $4 \mathrm{~h}$. The dried corncobs were pulverized into powder (20/60 mesh) using a JUNKE \& KUNKEL hammer mill. The ultimate analysis of the corncob was determined using a CHNS/O analyzer model 2400 from Perkin-Elmer, while the proximate analysis was conducted according to the procedure of ASTM. The results of ultimate and proximate analyses of the corncob are summarized in Table 1 .

Natural zeolite used in this research was obtained from Ponorogo, East Java, Indonesia. The purification of natural zeolite was conducted using hydrogen peroxide solution $\left(\mathrm{H}_{2} \mathrm{O}_{2}\right)$ at room temperature $\left(30^{\circ} \mathrm{C}\right)$ to remove organic impurities. The purified zeolite then was pulverized to particle size of $40 / 60$ mesh. The chemical composition of the purified natural zeolite was $\mathrm{SiO}_{2}(60.14 \%), \mathrm{Al}_{2} \mathrm{O}_{3}$ (12.52\%), $\mathrm{CaO}(2.51 \%), \mathrm{Fe}_{2} \mathrm{O}_{3}(2.49 \%), \mathrm{Na}_{2} \mathrm{O}(2.44 \%)$, $\mathrm{K}_{2} \mathrm{O}(1.28 \%), \mathrm{MgO}(0.49 \%), \mathrm{H}_{2} \mathrm{O}(14.40 \%)$, and loss on ignition $(3.73 \%)$.

All chemicals used in this study, such as sodium hydroxide $(\mathrm{NaOH})$, hydrochloric acid $(\mathrm{HCl})$, hydrogen peroxide $\left(\mathrm{H}_{2} \mathrm{O}_{2}\right)$, the standard reference of levulinic acid, etc., were purchased from Sigma Aldrich Singapore and directly used without any further purification.

\section{Natural zeolite modification}

The natural zeolite was modified using hydrochloric acid solution $(2 \mathrm{~N})$. The ratio between the zeolite powder and hydrochloric acid were 1:5, 1:10, and 1:15 (weight/volume). Thirty grams of zeolite powder were mixed with a certain volume of $\mathrm{HCl}$ solution and transferred into a round bottom flask. Subsequently the mixture was heated at $70{ }^{\circ} \mathrm{C}$ under reflux and continuous stirring at $500 \mathrm{rpm}$ for $24 \mathrm{~h}$. After the modification completed, the acid modified zeolite was separated from the mixture by vacuum filtration system. The solid was repeatedly washed with distilled

Table 1 Proximate and ultimate analysis of corncob and its pretreated form

\begin{tabular}{lcc}
\hline Component & Corncob, wt $\%$ & $\mathrm{NaOH}$ pretreated corncob, wt $\%$ \\
\hline Ultimate analysis (dry basis) & \\
Carbon & 54.1 & 53.8 \\
Hydrogen & 6.8 & 6.9 \\
Nitrogen & 0.3 & 0.2 \\
Sulfur & 0.1 & 0.1 \\
Oxygen & 38.7 & 39.0 \\
Proximate analysis (dry basis) & \\
Moisture content & 10.4 & 10.1 \\
Volatile matter & 67.1 & 71.8 \\
Fixed carbon & 19.4 & 15.2 \\
Ash & 3.1 & 2.9 \\
\hline
\end{tabular}


water to remove the excess $\mathrm{HCl}$ solution. The acid modified zeolite was dried in oven at $110{ }^{\circ} \mathrm{C}$ for $24 \mathrm{~h}$ to remove free moisture content. Then, modified zeolite was calcined in a furnace at a temperature of $400{ }^{\circ} \mathrm{C}$ for $4 \mathrm{~h}$.

\section{Delignification process}

Delignification process was carried out by soaking of corncob powder into $20 \%$ of $\mathrm{NaOH}$ solution. The ratio between solid and solution was 1:10 (weight/volume). The delignification process was conducted at a temperature of $30{ }^{\circ} \mathrm{C}$ under constant stirring (500 rpm). After the process completed $(24 \mathrm{~h})$, the treated corncob was separated from the liquid using vacuum filtration system. The biomass was repeatedly washed with distilled water until the $\mathrm{pH}$ of the washing solution around 6.5-7. Subsequently the treated corncob was dried at $110{ }^{\circ} \mathrm{C}$ for $24 \mathrm{~h}$.

\section{Conversion of corncob to levulinic acid}

The preparation of levulinic acid from corncob was conducted in a subcritical reactor system. The subcritical reactor system consists of $150 \mathrm{ml}$ high pressure stainless steel vessel, a pressure gage, an external electrical heating system, type K thermocouple, and M8 screws for tightening the reactor with its cap. The maximum allowable temperature and pressure of the vessel are $250{ }^{\circ} \mathrm{C}$ and $100 \mathrm{bar}$, respectively. The reaction experiments were conducted at a pressure of $30 \mathrm{bar}$ and three different temperatures $\left(180,200\right.$, and $\left.220^{\circ} \mathrm{C}\right)$. The typical reaction experiment is briefly described as follows: $20 \mathrm{~g}$ of corncob powder were mixed with $100 \mathrm{ml}$ of distilled water; subsequently $0.5 \mathrm{~g}$ of acid modified zeolite was added into the mixture. The mixture was heated until the desired temperature was reached, and during the heating process, the nitrogen gas was introduced to the system to maintain the water in the liquid condition. During the reaction process, the mixture was stirred at $300 \mathrm{rpm}$. After the hydrolysis time was reached $(30,45$, and $60 \mathrm{~min})$, the reactor was rapidly cooled to room temperature. The solid was separated from the liquid by centrifugation at $3000 \mathrm{rpm}$. The concentrations of levulinic acid and other organic substances, such as sugars, organic acids and HMF, were determined by high performance liquid chromatography (HPLC) analysis.

\section{Characterization of corncob and zeolite}

The chemical composition of the corncob and delignified corncob was determined using Thermal gravimetric Analysis (TGA). The analysis was performed on a TGA/ DSC-1 star system (Mettler-Toledo) with ramping and cooling rate of $10{ }^{\circ} \mathrm{C} / \mathrm{min}$ from room temperature to $800{ }^{\circ} \mathrm{C}$ under continuous nitrogen gas flow at a flowrate of $50 \mathrm{ml} / \mathrm{min}$. The mass of the sample in each measurement was $10 \mathrm{mg}$.

The surface topography of the corncob and zeolite catalysts was characterized using a field emission Scanning Electron Microscope (SEM), JEOL JSM 6390 equipped with backscattered electron (BSE) detector at an accelerating voltage of 15 and $20 \mathrm{kV}$ at a working distance of $12 \mathrm{~mm}$. Prior to SEM analysis, an ultra-thin layer of conductive platinum was sputter-coated on the samples using an auto fine coater (JFC-1200, JEOL, Ltd., Japan) for $120 \mathrm{~s}$ in an argon atmosphere.

The X-ray powder diffraction (XRD) analysis of the samples was performed on a Philips PANalytical X'Pert powder X-ray diffractometer with a monochromated high intensity $\mathrm{Cu} \mathrm{K} \alpha_{1}$ radiation $(\lambda=1.54056 \AA)$. The XRD was operated at $40 \mathrm{kV}, 30 \mathrm{~mA}$, and a step size of $0.05 \%$ from the $2 \theta$ angle between 5 and $90^{\circ}$.

The surface acidity of the zeolite acid activated zeolite was determined by amine adsorption analysis. A brief description of the method is as follows: a known amount of air dried zeolite or acid activated zeolite $(50 \mathrm{mg})$ were added into a series of test tubes. Subsequently, different volumes $(20-50 \mathrm{ml})$ of $n$-butylamine solution in benzene $(0.01 \mathrm{M})$ were added to the test tubes. The test tubes then tightly stoppered and stores at $30^{\circ} \mathrm{C}$. After the equilibrium condition was achieved, the remaining $n$-butylamine in the solution was determined by titration using $0.016 \mathrm{M}$ trichloroacetic acid solution in benzene, and 2,4 dinitrophenol was used as the indicator.

\section{HPLC analysis}

The organic compounds in the aqueous phase of the product from subcritical water process was analyzed using a Jasco chromatographic separation module consisting of a model PU-2089 quaternary low pressure gradient pump, a model RI-2031 refractive index detector and a model LCNetII/ADC hardware interface system. Prior to the injection in the HPLC system, all of the liquid samples were filtered through a $0.22 \mu \mathrm{m}$ PVDF syringe filter. The analysis of monomeric sugars was conducted with an Aminex HPX-87P sugar column (Bio-Rad, $300 \times 7.8 \mathrm{~mm}$ ) using degassed HPLC-grade water isocratically flowing at a rate of $0.60 \mathrm{ml} / \mathrm{min}$. The column was operated at $85{ }^{\circ} \mathrm{C}$. For the analysis of organic compounds, a Bio-Rad Aminex HPX$87 \mathrm{H}$ column $(300 \times 7.8 \mathrm{~mm})$ was used as the separating column. The isocratic elution of sulfuric acid aqueous solution $(5 \mathrm{mM})$ was used as the mobile phase with the flow rate of $0.6 \mathrm{ml} / \mathrm{min}$. The column oven was set at $55^{\circ} \mathrm{C}$. Details of the procedure can be seen elsewhere [12]. 


\section{Results and discussion}

To determine the chemical composition of corncob and sodium hydroxide treated corncob, the thermal gravimetric Analysis (TGA) was conducted under the nitrogen environment. The TGA curves of both samples are given in Fig. 1. At temperature between 50 and $200{ }^{\circ} \mathrm{C}$, the weight loss of corncob and the pretreated corncob mainly due to the evaporation of both free moisture content and bound water. From Fig. 1 it can be seen that a gradual thermal decomposition process with a significant weight loss for both samples (more than $60 \%$ ) are observed at a range of temperature from 250 to $400{ }^{\circ} \mathrm{C}$. This significant weight loss of the biomasses mainly due to the thermal decomposition of hemicellulose $\left(200-300{ }^{\circ} \mathrm{C}\right)$ and cellulose (300-360 ${ }^{\circ} \mathrm{C}$ ) into smaller molecular weight compounds, such as water, carbon dioxide, carbon monoxide, methane, and other organic compounds. Some of lignin also degraded at this range of temperatures, which mainly due to the breakdown of chemical bonds with low activation energy $[12,14]$. The breakdown of more stable bonds in the lignin occurred in temperature range from 400 to $500{ }^{\circ} \mathrm{C}$. At higher temperature (above $500{ }^{\circ} \mathrm{C}$ ), the weight loss of both biomasses was insignificant as seen in Fig. 1. The chemical compositions of corncob and its pretreated form which were determined by TGA method are listed in Table 2. Because the corncob contains high cellulose, this material is suitable as the raw material for levulinic acid production.

The SEM images of natural zeolite and acid modified zeolite are shown in Fig. 2. The modification using acid did not change the surface morphology of zeolite as indicated in Fig. 2. The XRD analysis was used to determine the crystalline structure of zeolite. In general, the modification using hydrochloric acid did not change or alter the crystalline structure of zeolite as shown in Fig. 3. The total

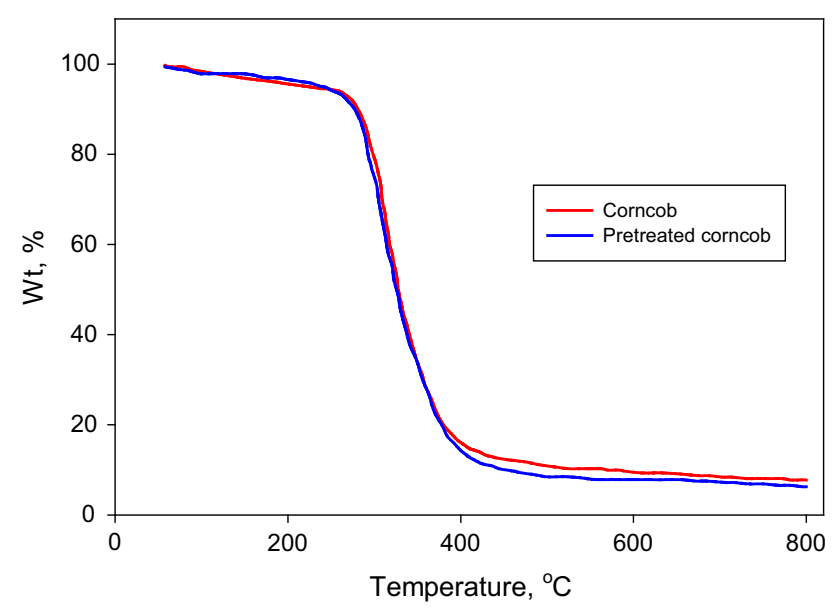

Fig. 1 Thermogravimetric curve of corncob and $\mathrm{NaOH}$ pretreated corncob surface acidity of natural zeolite was $0.517 \mathrm{mg} n$-butylamine/g and after modification using hydrochloric acid solution, the total surface acidity increased to $0.815 \mathrm{mg} n$ butylamine/g. The increase of surface acidity of acid modified zeolite due to the removal of some exchangeable cations $\left(\mathrm{Ca}^{2+}, \mathrm{Fe}^{3+}\right.$ and $\left.\mathrm{Al}^{3+}\right)$ from the framework of zeolite and replaced by $\mathrm{H}^{+}$.

The production of levulinic acid from lignocellulosic materials involves several complex reaction mechanisms which also producing several intermediate products. In the hydrolysis process, the cellulose is converted into glucose, while the hemicellulose is converted into hexose (glucose, mannose, and galactose) and pentose (xylose and arabinose). In the dehydration process, hexose will be converted into 5-hydroxy-methylfurfural (HMF) and pentose will be converted into furfural. The decomposition of HMF produces levulinic acid and formic acid. A byproduct produced during the process is humin, black insoluble polymeric materials.

The subcritical water process has unique behavior and has been known as a green process for several applications $[13,15,16]$. Under high temperature and pressure, the water dissociates into $\mathrm{H}_{3} \mathrm{O}^{+}$and $\mathrm{OH}^{-}$ions, and the presence of these excess ions indicates that the water can act as an acid or base catalyst. The subcritical water hydrolysis of pretreated corncob were conducted either with or without solid acid catalyst additions. The subcritical water hydrolysis products are summarized in Table 3. Without addition of solid acid catalyst, the breakdown of cellulose and hemicellulose into monomeric sugars significantly low as indicated in Table 3.

At subcritical condition the ion products $\left(\mathrm{H}_{3} \mathrm{O}^{+}\right.$and $\mathrm{OH}^{-}$) in water will make the water slightly acidic and at this condition the water become a good solvent for converting cellulose and hemicellulose to sugar monomers. The yield of monomeric sugars (calculated as the amount monomeric sugar/L solution) in the subcritical water process hydrolysis without the presence of catalyst increased with the increase of temperature from 180 to $220^{\circ} \mathrm{C}$ (from 1.54 to $2.62 \mathrm{~g} / \mathrm{L}$ ) as seen in Table 3 .

At constant pressure, the increase of temperature will decrease the dielectric constant of water and increase the ionization of water into $\mathrm{H}_{3} \mathrm{O}^{+}$and $\mathrm{OH}^{-}$leading to more acidic of the system. The presence of $\mathrm{H}_{3} \mathrm{O}^{+}$(hydroxonium) in the system represents the nature of the proton in aqueous solution and this proton subsequent attacks $\beta$-1,4-glycosidic bonds as the linking bonds of several monomeric Dglucose units in the long chain polymer of cellulose, and resulting $\mathrm{C}_{6}$ sugars as the product. The attack of hydroxonium ions into the linking bond of the hemicellulose chain, resulting $\mathrm{C}_{5}$ sugars as the product. With the increasing of temperature, the amount of hydroxonium ions also increase, therefore the breakdown of linking bonds of 
Table 2 Chemical composition of corncob and its pretreated

\begin{tabular}{lccl}
\hline Component & Corncob, wt $\%$ & NaOH pretreated corncob, wt $\%$ & TGA temperature, ${ }^{\circ} \mathrm{C}$ \\
\hline Water & 4.3 & 2.8 & $40-200$ \\
Hemicellulose & 13.1 & 11.3 & $200-300$ \\
Cellulose & 54.4 & 62.2 & $300-360$ \\
Lignin & 20.1 & 18.2 & $360-500$ \\
Ash + carbon & 8.1 & 5.5 & $>500$ \\
\hline
\end{tabular}
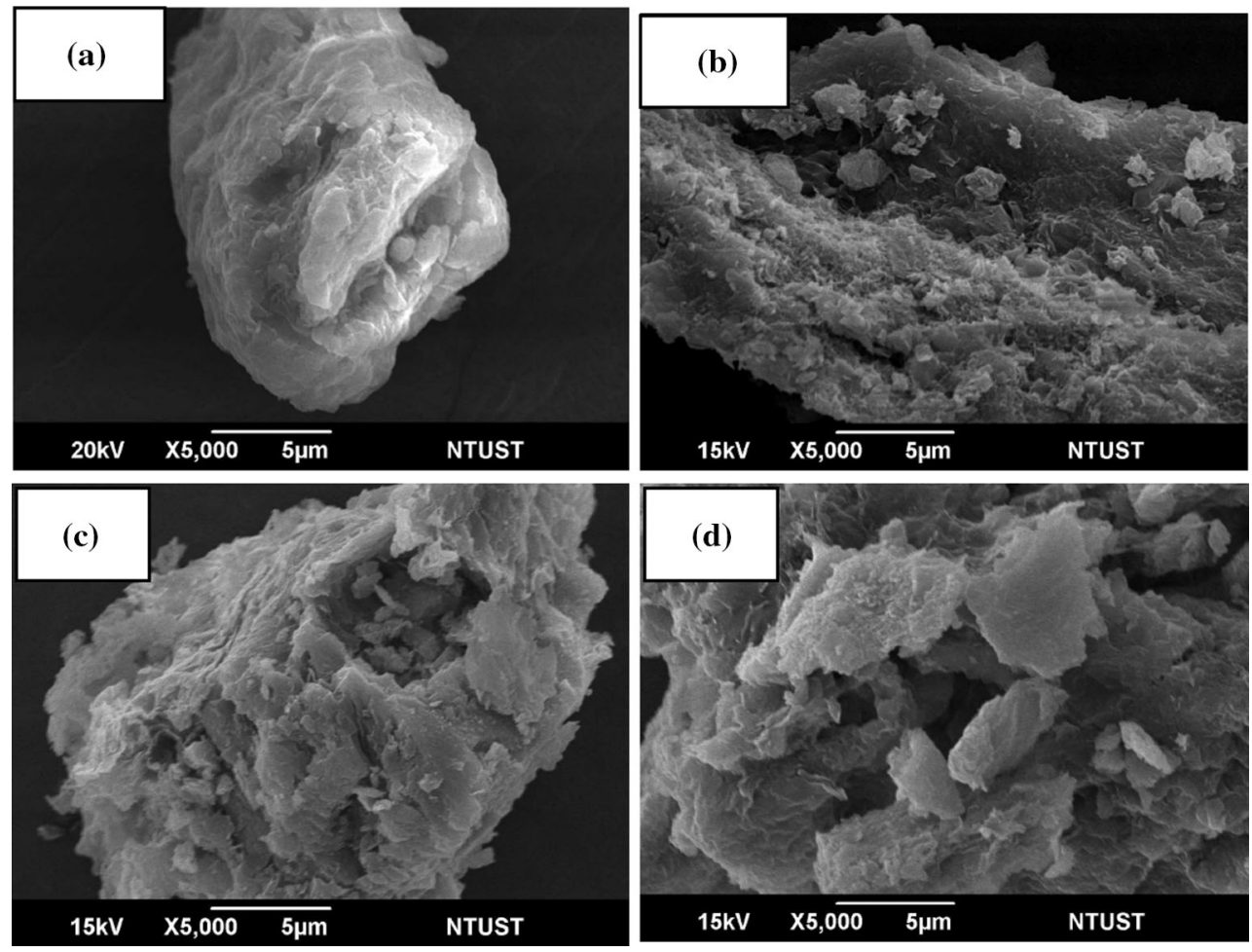

Fig. 2 SEM images of a natural zeolite, $\mathbf{b}$ modified zeolite (1:5), c modified zeolite (1:10), and $\mathbf{d}$ modified zeolite (1:15)

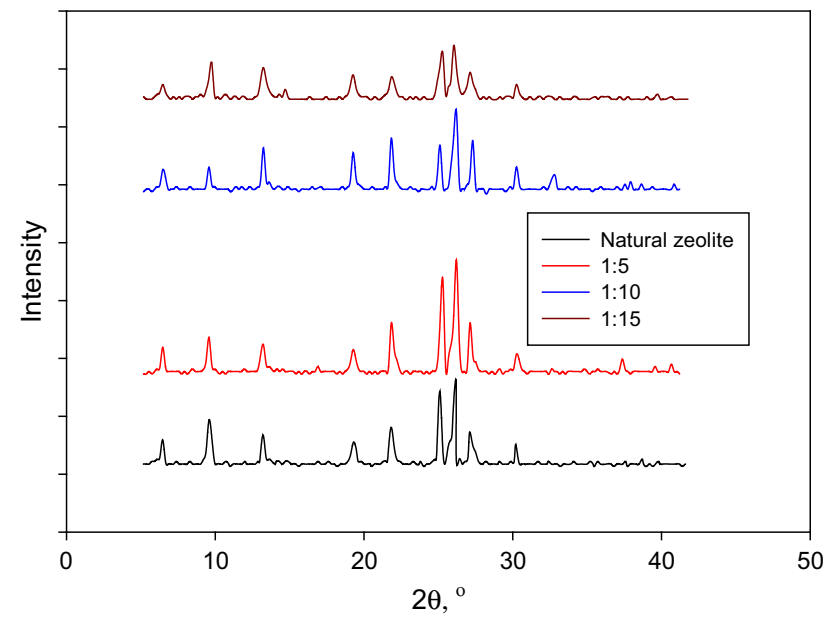

Fig. 3 X-Ray diffraction pattern of natural and acid modified zeolite the cellulose and hemicellulose became increase leading to the increase of yield of sugars.

The addition of solid acid catalyst (modified zeolite) into the system significantly enhanced the breakdown of cellulose and hemicellulose into monomeric sugars (clearly seen in the temperature range of $180^{\circ}-220^{\circ}$ ). The addition of the acid modified zeolite increased the number of protons (hydroxonium ions from subcritical water and $\mathrm{H}^{+}$ from the surface of acid modified zeolite), with the excess number of protons in the solution, the breakdown of linking bonds of the cellulose and hemicellulose became significantly increasing and as the results the yield of monomeric sugars also increases as seen in Table 3.

In the levulinic acid production process, the $\mathrm{C}_{6}$ sugars were dehydrated to HMF, this intermediate product subsequently converted into LA and formic acid. The $\mathrm{C}_{5}$ 
Table 3 Monomeric sugars in subcritical water hydrolysis product

\begin{tabular}{llrrrr}
\hline Temperature, ${ }^{\circ} \mathrm{C}$ & Acid activated zeolite, $\mathrm{g}$ & \multicolumn{2}{l}{ Yield mg/g dried corncob } & \\
\cline { 3 - 6 } & & Glucose & Xylose & Galactose & Arabinose \\
\hline 180 & 0 & 2.40 & 4.05 & 0.85 & 0.40 \\
& 0.5 & 55.65 & 40.20 & 27.40 & 14.55 \\
200 & 0 & 6.05 & 4.60 & 1.05 & 0.55 \\
& 0.5 & 82.55 & 57.75 & 42.55 & 36.10 \\
& 0 & 7.60 & 4.55 & 0.55 & 0.40 \\
& 0.5 & 120.65 & 76.90 & 47.60 & 42.20 \\
\hline
\end{tabular}

sugars were converted to furfural, and the later was further degraded into formic acid and other insoluble products [17]. In the first step of dehydration of glucose, the isomerization reaction of glucose-fructose occurred and subsequently it further dehydrated to HMF and the later converted rapidly to LA and formic acid. The temperature plays important role in the dehydration process of glucose into LA, since all the reactions were endothermic process, the increase of temperature also increases the rate of reaction and the yield of products also increase. At temperature above $180{ }^{\circ} \mathrm{C}$, the isomerization reaction of glucose-fructose occurred much faster, and more HMF was produced during the process, however, based on the kinetic parameters for the hydrolysis of sugarcane bagasse proposed by Girisuta et al. [17], the formation of LA or dehydration of HMF is much faster than other reactions. As soon as the HMF formed it was instantaneously converted to LA.

To obtain optimum process parameters for the levulinic acid production from corncob using catalytic subcritical water process, the response surface methodology (RSM) was employed to analyze the experimental data. The following polynomial equation was fitted to the response resulted from RSM by the LSM (least square method):

$Y=\alpha_{o}+\sum_{i-1}^{k} \alpha_{i} X_{i}+\sum_{i=1}^{k} \alpha_{i i} X_{i}^{2}+\sum_{i=1}^{k-1} \sum_{j=i+1}^{k} \alpha_{i j} X_{i} X_{j}$

where $Y$ is the concentration of levulinic acid $\left(C_{\mathrm{LA}}\right)$ in the product, $\alpha_{o}$ is a constant coefficient, $\alpha_{I}$ are the linear coefficients, $\alpha_{i j}$ are the interaction coefficients, and $\alpha_{i i}$ are the quadratic coefficients. $X_{i}$ and $X_{j}$ are the codec values of the variables. The independent variables used in this study were ratio of zeolite and acid $(R)$, temperature $\left(T,{ }^{\circ} \mathrm{C}\right)$, and reaction time $(t, \mathrm{~min})$. The regression model was calculated using Minitab 16.1.1 Statistical software to estimate the response of dependent variables. The analysis of variance (ANOVA) was employed to confirm the adequacy of the model parameters. The suitability of the model to represent the data was determined by the value of $R^{2}$.
The full quadratic model that describes the relationship between the effects of ratio of zeolite and acid $(R)$, temperature $\left(T,{ }^{\circ} \mathrm{C}\right)$, and reaction time $(t, \min )$ on the concentration of levulinic acid is given as follow

$$
\begin{aligned}
C_{\mathrm{LA}}= & 37102.7+5393.3 R+3893.3 T \\
& +6040.8 t-254.5 R^{2}-14713.5 T^{2}+1485.8 t^{2} \\
& +689.4 R T+1993.5 R t-1039.5 T t .
\end{aligned}
$$

$p$ value of the quadratic model $(<0.0001)$ was significant at the probability level of $5 \%\left(R^{2}=0.9614\right)$. The first order effect of variables $R, T$, and $t$ on the output parameter $\left(C_{\mathrm{LA}}\right)$ were significant at the confidence level of $95 \%$. However, the second order effect of $R$ and $t$ as well as the interactions between $R$ and $t, R$ and $T, T$ and $t$ were insignificant as indicated in Table 4. Re-arrangement of Eq. (2) with the inclusion only the significant parameters give the following result:

$$
\begin{aligned}
C_{\mathrm{LA}}= & 37102.7+5393.3 R+3893.3 T \\
& +6040.8 t-14713.5 T^{2} .
\end{aligned}
$$

The effects of ratio of zeolite and acid $(R)$, temperature $(T)$ and time $(t)$ of subcritical water hydrolysis on the concentration of levulinic acid are plotted as surface plots in Figs. 4, 5 and 6. Both of these parameters have positive effects on the yield of levulinic acid (concentration). As mentioned before that temperature play important role both in hydrolysis and hydration processes, by increasing temperature the formation of levulinic acid or dehydration of HMF is much faster than other reactions. However, if the temperature is too high and the activation energy of the formation of humin is achieved, the degradation of HMF into humin is faster than the dehydration of HMF into levulinic acid and this phenomenon decreases the yield of levulinic acid. By increasing the subcritical hydrolysis time, the contact between the cellulose and hemicellulose with the ionic product of water $\left(\mathrm{H}_{3} \mathrm{O}^{+}\right.$and $\left.\mathrm{OH}^{-}\right)$become more intense and longer, and more of the cellulose and hemicellulose molecules were hydrolyzed and converted into monomeric sugars and subsequently dehydrated into HMF and levulinic acid. The ratio of zeolite and 
Table 4 Analysis of variance for concentration of levulinic acid as a function of ratio of zeolite and acid $(R)$, temperature $\left(T,{ }^{\circ} \mathrm{C}\right)$, and reaction time $(t, \min )$

\begin{tabular}{lrrrrrr}
\hline Source & DF & \multicolumn{1}{c}{ Seq SS } & \multicolumn{1}{l}{ Adj SS } & \multicolumn{1}{l}{ Adj MS } & \multicolumn{1}{l}{$F$} & $p$ value \\
\hline Regression & 9 & $1,498,173,667$ & $1,498,173,667$ & $166,463,741$ & 39.05 & 0.000 \\
Linear & 3 & $645,895,733$ & $645,895,733$ & $215,298,578$ & 50.51 & 0.000 \\
$R$ & 1 & $232,702,558$ & $232,702,558$ & $232,702,558$ & 54.59 & 0.001 \\
$T$ & 1 & $121,263,058$ & $121,263,058$ & $121,263,058$ & 28.45 & 0.000 \\
$t$ & 1 & $291,930,117$ & $291,930,117$ & $291,930,117$ & 68.48 & 0.000 \\
Square & 3 & $830,159,318$ & $830,159,318$ & $276,719,773$ & 64.91 & 0.000 \\
$R^{2}$ & 1 & $5,369,842$ & 239,105 & 239,105 & 0.06 & 0.822 \\
$T^{2}$ & 1 & $816,638,331$ & $799,339,635$ & $799,339,635$ & 187.51 & 0.000 \\
$t^{2}$ & 1 & $8,151,145$ & $8,151,145$ & $8,151,145$ & 1.91 & 0.225 \\
Interaction & 3 & $22,118,617$ & $22,118,617$ & $7,372,872$ & 1.73 & 0.276 \\
$R T$ & 1 & $1,900,814$ & $1,900,814$ & $1,900,814$ & 0.45 & 0.534 \\
$R t$ & 1 & $15,895,770$ & $15,895,770$ & $15,895,770$ & 3.73 & 0.111 \\
$T t$ & 1 & $4,322,033$ & $4,322,033$ & $4,322,033$ & 1.01 & 0.360 \\
Residual error & 5 & $21,314,232$ & $21,314,232$ & $4,262,846$ & & \\
Lack-of-fit & 3 & $20,009,560$ & $20,009,560$ & $6,669,853$ & 10.22 & 0.090 \\
Pure error & 2 & $1,304,673$ & $1,304,673$ & 652,336 & & \\
Total & 14 & $1,519,487,900$ & & & & \\
\hline
\end{tabular}

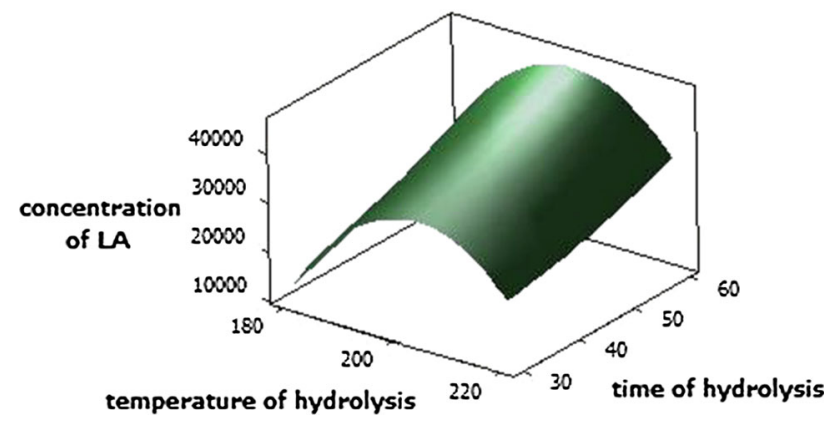

Fig. 4 Surface plot of concentration levulinic acid as a function of temperature and time of subcritical water hydrolysis

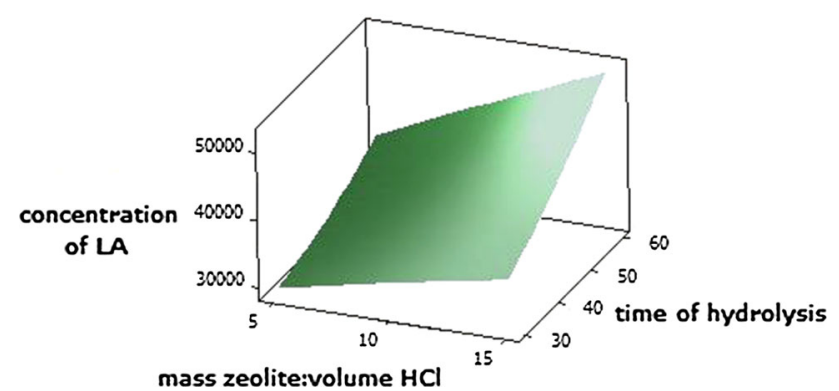

Fig. 5 Surface plot of concentration levulinic acid as a function of ratio of zeolite and acid, and time of subcritical water hydrolysis

hydrochloric acid also had a positive effect on the concentration of levulinic acid, by increasing of the ratio of acid, the ion exchange between some metal cations with $\mathrm{H}^{+}$also increased. Subsequently, with the increased of $\mathrm{H}^{+}$ in the surface of zeolite catalyst also increased the number

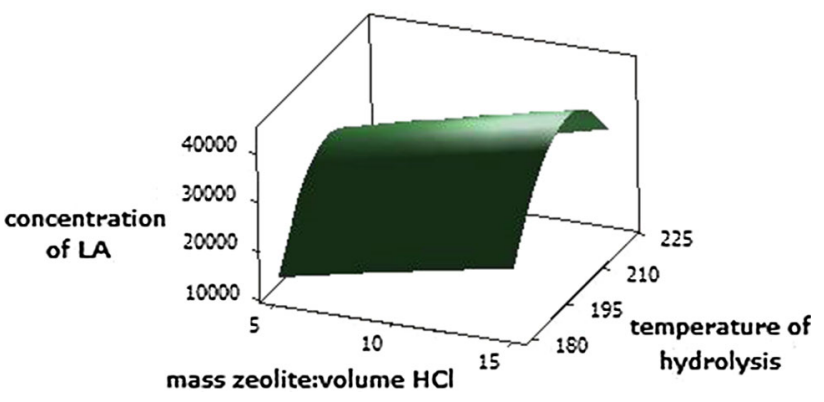

Fig. 6 Surface plot of concentration levulinic acid a function of ratio of zeolite and acid, and temperature of subcritical water hydrolysis

of protons in the solution leading to the increase of the breakdown of linking bonds of the cellulose and hemicellulose to produce monomeric sugars. These monomeric sugars under acidic condition and high temperature were dehydrated into levulinic acid. The experimental results of the effects of temperature, reaction time, and the ratio of zeolite and hydrochloric acid (activation of zeolite) on the yield of levulinic acid are given in Table 5.

To obtain the maximum yield or concentration of levulinic acid is an important point in this study to establish an efficient process. This objective can be achieved through the setting of all significant parameters at optimum conditions. The optimum condition of the production of levulinic acid from corncob through subcritical water process is depicted in Fig. 7. RSM indicates the optimum conditions for the variable of ratio of zeolite and acid was coded 1 , variable of hydrolysis temperature was coded 0.1111 and hydrolysis time was coded 1 . These units 
Table 5 The effect of temperature and reaction time on the yield of levulinic acid

\begin{tabular}{llll}
\hline Temperature, ${ }^{\circ} \mathrm{C}$ & Time of hydrolysis, $\min$ & Ratio zeolite: volume $\mathrm{HCl}, \mathrm{g}: \mathrm{ml}$ & Yield of levulinic acid, mg/g dried corncob \\
\hline 180 & 30 & $1: 10$ & 73.8 \\
180 & 45 & $1: 5$ & 69.5 \\
180 & 45 & $1: 15$ & 114.7 \\
180 & 60 & $1: 10$ & 129.3 \\
200 & 30 & $1: 5$ & 138.4 \\
200 & 30 & $1: 15$ & 174.3 \\
200 & 45 & $1: 10$ & 181.9 \\
200 & 60 & $1: 5$ & 194.2 \\
200 & 60 & $1: 15$ & 269.9 \\
220 & 30 & $1: 10$ & 119.8 \\
220 & 45 & $1: 5$ & 104.9 \\
220 & 45 & $1: 15$ & 163.9 \\
220 & 60 & $1: 10$ & 154.4 \\
\hline
\end{tabular}

Fig. 7 Independent factor optimization during subcritical water hydrolysis and hydration processes of corncob

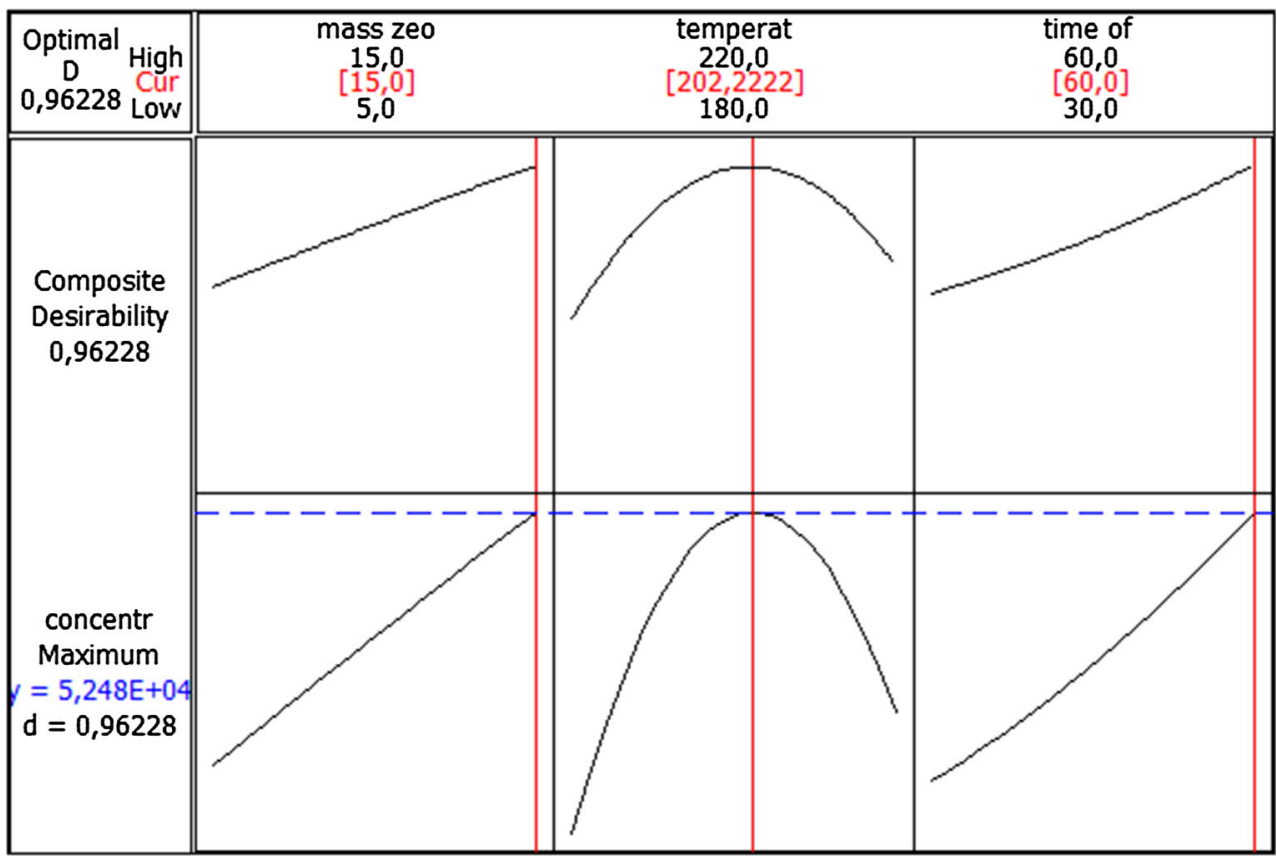

The stability and reusability of the heterogeneous catalyst are crucial issues for industrial application. To examine the stability and reusability of acid modified zeolite, the catalyst was recovered from the reaction mixture, re-calcined at $400{ }^{\circ} \mathrm{C}$ for $4 \mathrm{~h}$, and reused five times. The reaction temperature of $200{ }^{\circ} \mathrm{C}$, reaction time of $60 \mathrm{~min}$, and zeolite to acid ratio of $1: 15$ were used as the reaction parameters to study of the reusability of catalyst. The reusability results of the spent catalyst are depicted in Fig. 8. This figure clearly shows that the yield of levulinic acid gradually decrease after the first run. This phenomenon indicates that the catalyst has gradually deactivated during the reaction 


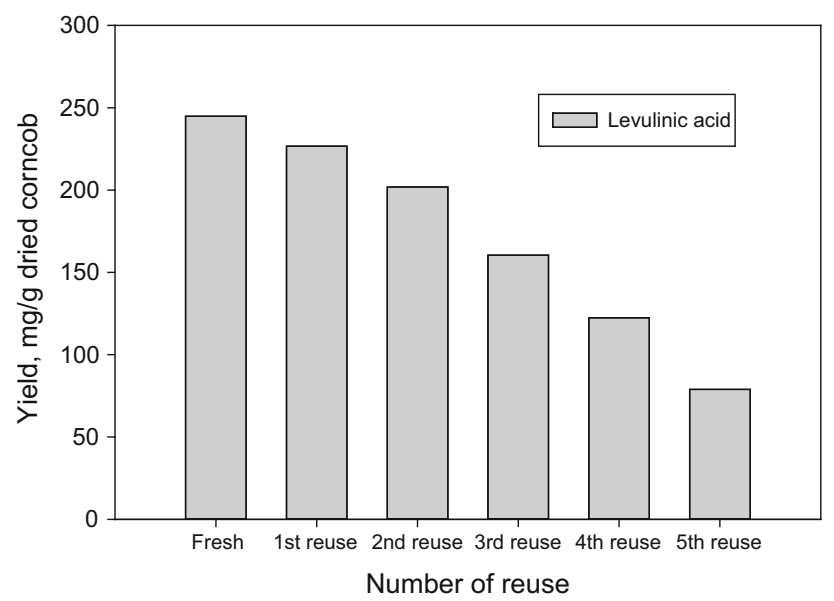

Fig. 8 The stability and reusability of spent catalyst

cycle. The activation of catalyst during the reaction cycle due to the leaching of surface acid sites (the acidity of fresh catalyst was $0.815 \mathrm{mg} n$-butylamine/g and after 5 th cycle was $0.423 \mathrm{mg} n$-butylamine/g) and the formation of humin in the active sites of the catalyst.

\section{Conclusion}

Corncob had been successfully used as the new raw material for levulinic acid production. The production of levulinic acid was conducted in subcritical condition with the presence of acid modified zeolite as catalyst. The yield of levulinic acid in the final product was strongly influenced by the ratio of zeolite and acid, reaction temperature, and reaction time. The optimum yield of levulinic acid was $262.4 \mathrm{mg} / \mathrm{g}$ dried corncob, and was obtained at temperature of $200{ }^{\circ} \mathrm{C}$, reaction time of $60 \mathrm{~min}$, and zeolite to acid ratio of 1:15.

Acknowledgments The financial support from The World Academy of Science Research Grant 2015/2016 with contract no 14-095/RG/ CHE/AS-1; UNESCO FR:325028591 and LPPM Widya Mandala Surabaya Catholic University through Outstanding Lecturer Research Grant 2014/2015 with contract number $845 \mathrm{a} / \mathrm{WM} 01.5 / \mathrm{N} / 2014$ is gratefully acknowledged.

Authors' contributions CDH, KJM and JNP conducted the experiments, while DANS performed the statistical analysis, FES and YHJ drafting the manuscript, SI performed the experiment design and corrected the manuscript.

\section{Compliance with ethical standards}

Conflict of interest The authors declare that they have no competing interests.

Open Access This article is distributed under the terms of the Creative Commons Attribution 4.0 International License (http://crea tivecommons.org/licenses/by/4.0/), which permits unrestricted use, distribution, and reproduction in any medium, provided you give appropriate credit to the original author(s) and the source, provide a link to the Creative Commons license, and indicate if changes were made.

\section{References}

1. Cavinato G, Toniolo L (1990) Levulinic acid synthesis via regiospecific carbonylation of methyl vinyl ketone or of its reaction products with hydrochloric acid or an aleanol or of a mixturjz of acetone with a formaldehyde precursor catalyzed by a highly active Pd-HCl system. J Mol Catal 58:251-267

2. Mukherjee A, Dumont MJ, Raghavan V (2015) Review: sustainable production of hydroxymethylfurfural and levulinic acid: challenges and opportunities. Biomass Bioenergy 72:143-183

3. Ramli NAS, Amin NAS (2015) Fe/HY zeolite as an effective catalyst for levulinic acid production from glucose: characterization and catalytic performance. Appl Catal B Environ 163:487-498

4. Chamnankid B, Ratanatawanate C, Faungnawakij K (2014) Conversion of xylose to levulinic acid over modified acid functions of alkaline-treated zeolite $\mathrm{Y}$ in hot-compressed water. Chem Eng J 258:341-347

5. Lourvanij K, Rorrer GL (1994) Dehydration of glucose to organic acids in microporous pillared clay catalysts. Appl Catal A 109:147-165

6. Jow J, Rorrer GL, Hawley MC, Lamport DTA (1987) Dehydration of D-fructose to levulinic acid over LZY zeolite catalyst. Biomass 14:185-194

7. Girisuta B, Danon B, Manurung R, Janssen LPBM, Heeres HJ (2008) Experimental and kinetic modelling studies on the acidcatalysed hydrolysis of the water hyacinth plant to levulinic acid. Bioresour Technol 99:8367-8375

8. Ya'aini N, Amin NAS, Asmadi M (2012) Optimization of levulinic acid from lignocellulosic biomass using a new hybrid catalyst. Bioresour Technol 116:58-65

9. Deng W, Zhang Q, Wang Y (2014) Catalytic transformations of cellulose and cellulose-derived carbohydrates into organic acids. Catal Today 234:31-41

10. Lourvanij K, Rorrer GL (1993) Reactions of aqueous glucose solutions over solid-acid Y-zeolite catalyst at $110-160{ }^{\circ} \mathrm{C}$. Ind Eng Chem Res 32:11-19

11. Zeng W, Cheng DG, Zhang H, Chen F, Zhan X (2010) Dehydration of glucose to levulinic acid over MFI-type zeolite in subcritical water at moderate conditions. React Kinetics Mech Catal 100:377-384

12. Putro JN, Kurniawan A, Soetaredjo FE, Lin SY, Ju YH, Ismadji S (2015) Production of gamma-valerolactone from sugarcane bagasse over $\mathrm{TiO} 2$-supported platinum and acid-activated bentonite as co-catalyst. RSC Adv 5:41285-41299

13. Ahmed IN, Nguyen PLT, Huynh LH, Ismadji S, Ju YH (2013) Bioethanol production from pretreated Melalueca leucadendron shedding bark-simultaneous saccharification and fermentation at high solid loading. Bioresour Technol 136:213-221

14. Yang H, Yan R, Chen H, Lee DH, Zheng C (2007) Characteristics of hemicellulose, cellulose and lignin pyrolysis. Fuel 86:1781-1788

15. Tsigie YA, Huynh LH, Ismadji S, Engida AM, Ju YH (2012) Insitu biodiesel production from wet Chlorella vulgaris under subcritical condition. Chem Eng J 213:104-108

16. Go AW, Sutanto S, Nguyen PLT, Ismadji S, Gunawan S, Ju YH (2014) Biodiesel production under subcritical condition using subcritical water treated whole Jatropha curcas seed kernels and possible use of hydrolysates to grow Yarrowia lipolytica. Fuel 120:46-52

17. Girisuta B, Dussan K, Haverty D, Leahy JJ, Hayes MHB (2013) A kinetic study of acid catalysed hydrolysis of sugar cane bagasse to levulinic acid. Chem Eng J 217:61-70 